\title{
A ATUALIDADE DA CONCEPÇÃO DE RADICALIDADE EM PAULO FREIRE NOS PRIMEIROS ESCRITOS NO EXÍLIO: DELINEAMENTOS PARA PRÁTICAS EDUCATIVAS NA DIREÇÃO DA EMANCIPAÇÃO HUMANA
}

\author{
Eliana de Sousa Alencar Marques \\ Universidade Federal do Piauí (UFPI), Teresina, Piauí, Brasil \\ Josiane SOUSA Costa de Oliveira \\ Instituto Federal do Maranhão (IFMA), Timon, Maranhão, Brasil \\ LUIZ Jesus SANTOS BONFIM \\ Universidade Federal do Piauí (UFPI), Teresina, Piauí, Brasil
}

\begin{abstract}
Resumo: Este texto objetiva analisar a concepção de radicalidade humanizadora em Paulo Freire e as determinações que esse conceito engendra às práticas educativas com vistas à emancipação humana. Ele resulta de pesquisa bibliográfica nas obras "Pedagogia do Oprimido" (2013) e "Educação como prática de liberdade" (2015), e nas reflexões de apropriadores. A radicalidade humanizadora em Freire é produto da sua práxis, resultado da sua busca para compreender melhor os elementos da realidade e atuar de forma consciente rumo à transformação da realidade social. Com efeito, a radicalidade de Freire é humanizadora porque defende a emancipação humana. É humanizador salvaguardar a possibilidade de emancipação e da constituição do ser mais dos indivíduos a partir da construção coletiva e ativa, envolvendo diretamente os oprimidos.
\end{abstract}

Palavras-chave: Pedagogia Freireana. Radicalidade. Transformação Social. Práticas Educativas.

\section{INTRODUÇÃO}

Para Gadotti (1996), a radicalidade é uma característica presente em toda trajetória teórico-prática de Paulo Freire. Após sua prisão, decorrente do golpe militar de 1964, no Brasil, Freire foi viver no Chile. De acordo com Willianson (1996), essa experiência exerceu forte contribuição para a radicalização do pensamento e da prática do educador pernambucano. Seus primeiros escritos no exílio resultam de sistematizações teóricas, produto da sua experiência vivida no Brasil nas décadas de 1950 e 1960, acrescidas da sua atuação no Chile.

Guardadas as devidas proporções, a partir da segunda metade da década de 2010, assistimos o Brasil passar por uma espécie de retorno ao cenário do golpe de 1964, que, na época, culminou no exílio de Paulo Freire. A disputa ideológica em nosso país regressa com força e reverbera em discursos já conhecidos da população brasileira, tais como: "combate ao comunismo"; "em defesa de Deus e da família"; "Brasil: ame-o ou deixe-o". Entretanto, se observa que, sob o véu da "defesa da democracia" e da 
"manutenção da ordem", forças reacionárias e conservadoras vêm tomando assento e conseguindo implementar a política de desmonte e de aprofundamento das desigualdades sociais, tendo em conta o congelamento de investimento de recursos públicos por 20 anos - Proposta de Emenda Constitucional (PEC-241) que congelou o teto de investimento do Governo em diversas áreas, dentre elas educação e saúde -; a retirada de direitos trabalhistas e os sucessivos ataques às políticas sociais progressistas relacionadas a gênero, à raça, à sexualidade, entre outras.

Diferente de 1964, no contexto do Brasil atual, a efetivação do golpe não precisou da força militar ostensiva, mas continua a contar com velhos parceiros: grande imprensa, representantes do poder econômico local e mundial, classe média conservadora descontente, elites empresariais, sectarismo religioso. Junto a esses já conhecidos, entram em cena novos protagonistas. Um dos principais foi a participação ativa das redes sociais na disseminação das fake news, que ajudaram a sustentar a narrativa de combate à corrupção e ao comunismo. Outro protagonista alvissareiro foi o impeachment de uma presidenta democraticamente eleita sem que ela tenha cometido nenhum crime que justificasse tal processo, fato que acabou por "legitimar" o impedimento dentro dos limites "republicanos democráticos" em substituição aos tanques e ao exército nas ruas.

O retorno do debate ideológico e da polarização trouxe a necessidade de materializar o "inimigo invisível" em nomes, instituições, políticas públicas. No âmbito dos alvos concretos e simbólicos a combater, a educação emerge como central. Basta observar que a reforma do ensino médio e a Base Nacional Curricular Comum (BNCC) foram aprovadas "a toque de caixa". Na esfera do financiamento da educação, a ofensiva contra ela congela e reduz repasses de forma sistemática para universidades e financiamento de pesquisas, além de promover ataques deliberados aos docentes e pesquisadores que se colocam contra a onda fascista crescente no país.

No contexto dessa ofensiva contra a educação, chama a atenção a concentração dos ataques à figura e ao legado de Paulo Freire, como um dos alvos preferenciais dos "defensores da democracia, da família e dos bons costumes". Prova disso é a reiterada tentativa de supressão do título de patrono da educação brasileira.

Com efeito, esse incômodo provocado pelo legado de Freire, contraditoriamente, tem servido, antes de qualquer coisa, para revelar a atualidade do seu pensamento, da sua crítica e a necessidade de atuação cada vez mais radical no enfrentamento da marginalização da grande parcela de brasileiros e brasileiras desassistidos pelo poder público em todas as dimensões da sua existência. Os últimos anos de reformas ultraliberais e do avanço de pautas conservadoras e reacionárias exigem de nós educadores e educadoras que assumamos nossa condição de seres ontocriativos para fazer frente, de forma radical, no sentido freireano, à tão destoante realidade.

Dessa forma, pensando nas contribuições freireanas, principalmente aquelas resultado das reflexões dos primeiros anos de exílio, buscamos, neste texto, discutir a atualidade da radicalidade humanizadora da educação em Freire nas obras "Educação Como Prática da Liberdade" e "Pedagogia do Oprimido" - publicadas pela primeira vez em 1967 e 1968, respectivamente -, partindo da seguinte questão: qual a concepção de 
MARQUES, E. de S. A.; OLIVEIRA, J. S. C. de; BONFIM, L. J. S.

radicalidade expressa por Freire nos primeiros escritos sobre educação quando se encontrava no exílio e de que modo podem estes determinar práticas educativas na direção da emancipação humana na atualidade? Diante da questão em tela, o objetivo do artigo é analisar a concepção de radicalidade humanizadora em Freire e as determinações que esse conceito engendra às práticas educativas com vistas à emancipação humana.

O texto está organizado em duas partes, sendo que, na primeira, discutimos o sentido que a categoria radicalidade assume na obra de Paulo Freire; na segunda, refletimos especialmente acerca da educação como processo humanizador, sem desconsiderar as possibilidades e os limites com os quais nos deparamos ao tentarmos realizar tal projeto educativo no cenário atual em que se encontra a sociedade brasileira. Nas considerações finais, reunimos apontamentos indicadores de que o projeto educativo freireano é radicalmente humanizador porque, longe de se pautar numa visão ingênua, é sobretudo crítico e orientado para a formação de seres humanos com tendências à emancipação.

\section{A RADICALIDADE EM PAULO FREIRE NOS PRIMEIROS ESCRITOS DURANTE O EXÍLIO}

A vida e a obra de Paulo Freire foram marcadas pela radicalidade, característica, conforme Gadotti (1996), que esteve presente em toda sua trajetória. Em entrevista ao professor Niedson Rodrigues (1995, p. 323), dois anos antes de sua morte, ele fala dessa permanência, ao ser indagado acerca do "[...] que permaneceu e o que se modificou no homem de ação e no intelectual Paulo Freire, ao longo dos últimos 30 anos?":

\footnotetext{
Tenho medo de, ao responder a essa pergunta, ficar, aparentemente, pouco humilde, porque se eu disser: 'Olha, eu venho mais é me radicalizando', parece que a gente fez tantas coisas mais ou menos boas, há 30 anos, que não achou que devesse mudá-las, apenas radicalizá-las, o que é uma forma de juntar algum tempero novo (RODRIGUES, 1995, p. 323).
}

Pelo excerto acima, podemos inferir que a radicalidade, em Freire, assim como as demais categorias que ganham vida em seus escritos formando a força do seu pensamento, está sempre em movimento, não expressa ideias ou conceitos estáticos, absortos no tempo, imbrica-se ao seu estar no mundo e com o mundo, o que exige de nós esforço para responder às seguintes questões: qual concepção de radicalidade se encontra nos primeiros escritos do exílio que permanecem em toda trajetória do educador pernambucano? Em que se diferenciam e se aproximam dos significados correntes do vocábulo?

A discussão da concepção freireana de radicalidade presente nos primeiros escritos exige retomada à etimologia da palavra. Conforme dados do site Dicionário Etimológico, a origem da palavra radical vem do latim radix, que significa "raiz". Na língua portuguesa, a palavra "radical" se originou a partir do latim radicalis, que significa "relativo à raiz", ou seja, radicalis é uma derivação de radix, que quer dizer "raiz".

O significado do termo latino tinha sentido filosófico atribuído ao fato de alguém ou algo "ter raízes", ou seja, "ter origens". E, a partir do século XVII, esse termo 
passou a significar "a essência de algo" ou "ir de encontro à origem de algo".

Ao pesquisarmos no site Dicio, Dicionário on-line de Português, temos o termo radicalismo como um modo de agir de quem é radical, intransigente, inflexível; [Política] "Sistema político segundo o qual uma sociedade deverá ser alvo de mudanças profundas, além de passar por uma completa transformação de sua organização social." (DÍCIO, 2021).

Como podemos observar, existem significados e usos distintos para o termo radical. Em suma, a opção pelo uso de quaisquer de seus significados requer cuidado, especialmente porque pode assumir contornos distorcidos a depender da visão de mundo, de sociedade e das intencionalidades de quem os utiliza.

Na obra "Educação como Prática da Liberdade", publicada pela primeira vez em 1967, Paulo Freire sistematiza, no exílio no Chile, sua experiência no Brasil na década de 1950 e nos primeiros anos da década de 1960, que antecederam ao golpe militar de 1964. Nessa obra, encontramos os primeiros contornos da concepção de radicalização assumida pelo autor, compreendida como um enraizamento crítico realizado de forma opcional pelo ser humano. Por ser uma opção crítica, para Freire, é uma escolha amorosa, comunicativa e humilde, exatamente por não negar ao outro a oportunidade de optar, sem, contudo, abandonar convicções, pois,

\footnotetext{
[...] respeita no outro o direito de também julgar-se certo. Tenta convencer e converter, e não esmagar o seu oponente. Tem o dever, contudo, por uma questão mesma de amor, de reagir à violência dos que the pretendam impor silêncio. Dos que, em nome da liberdade, matam, em si e nele, a própria liberdade. A posição radical, que é amorosa, não pode ser autoflageladora. Não pode acomodar-se passivamente diante do poder exacerbado de alguns que leva à desumanização de todos, inclusive dos poderosos (FREIRE, 2015, p. 51, grifos nossos).
}

Nessas primeiras aproximações da radicalidade em Freire, percebemos a contraposição dessa concepção à imposição de ideias e, ao mesmo tempo, seu compromisso com a comunicação para o convencimento. Nesse sentido, o autor pernambucano buscava entender a essência das coisas, ao passo que buscava levar essa concepção à sua prática, que retornava novamente para enriquecer essa compreensão.

Portanto, essa radicalidade se erige a partir de atitude contrária à passividade, mas nem por isso deixando de ser amorosa, pois se preocupa com o outro, com a oportunidade dele se expressar. Essa posição significa dar o direito ao outro de optar, de refletir coletivamente sobre suas posições, sem que, para isso, seja necessário renunciar certezas, mas oportunizar a reflexão, o momento de contraposição. Em outras palavras, não cercear a liberdade dos outros sob o pretexto do discurso da liberdade. Portanto, a radicalização em Freire não exclui, não divide ou separa as pessoas, afastando-se, assim, do sentido de intransigência.

De acordo com Freire (2013), aquele que não se comunica, que não dialoga, excluindo o outro da oportunidade de optar e se expressar, não é o radical, mas o sectário. Essa distinção realizada pelo autor entre a radicalidade e o sectarismo é um 
ponto importante para afastar a pecha de extremista do seu pensamento.

É importante ressaltar que o significado de radicalidade como sinônimo de violência, fanatismo e irracionalismo é imposto não só a Freire, mas aos que se contrapõem à opressão, à hegemonia de discursos e práticas que retiram a liberdade e a possibilidade de as pessoas serem mais humanizadas. Na "Nota 16", do livro "Educação Como Prática da Liberdade", o autor adverte sobre a tentativa de definir o que é violência pelas mesmas pessoas que a exercem contra os oprimidos.

Portanto, conforme Freire (2015, p. 51), os sectários, os extremistas não são radicais, pois se utilizam da arrogância ao invés da humildade, são contra o diálogo, além de agirem pela emoção, mas de forma acrítica e irracional. Nesse sentido, a sectarização,

\begin{abstract}
É reacionária, seja assumida por direitista, que para nós é um sectário de "nascença", ou esquerdista. O sectário nada cria porque não ama. Não respeita a opção dos outros. Pretende a todos impor a sua, que não é opção, mas fanatismo. Daí a inclinação do sectário ao ativismo, que é ação sem vigilância da reflexão. Daí o seu gosto pela sloganização, que dificilmente ultrapassa a esfera dos mitos e, por isso mesmo, morrendo nas meias verdades, nutre-se do puramente "relativo a que atribui valor absoluto" (FREIRE, 2015, p. 51 , grifos nossos).
\end{abstract}

Nessa direção, ao fazer a crítica à postura sectária, o autor chama a atenção para a importância do diálogo, da apreensão pela comunicação da essência dos fenômenos em contraposição aos mitos e à retórica aparente dos discursos. A radicalidade busca sair da esfera emotiva, visando compreender as causas, para a prática consciente que supere tanto o ativismo quanto o discurso vazio.

Na obra "Pedagogia do Oprimido", publicada em 1968, Freire (2013) segue discutindo a radicalização em contraposição à sectarização. Esta última compreendida como castradora orientada pelo fanatismo, enquanto a radicalização é criadora por utilizar a criticidade como fundamento. Nessa perspectiva, a sectarização vai alienar por se orientar pelo mito, enquanto a radicalização liberta, "[...] porque, implicando o enraizamento que os homens fazem na opção que fizeram, os engaja cada vez mais no esforço de transformação da realidade concreta, objetiva." (p. 25).

Desse modo, o autor ratifica a importância da atitude radical em contraposição ao sectarismo, no sentido de compreensão da essência da realidade com o objetivo de transformá-la concretamente. O ativismo impulsionado por uma compreensão mítica da realidade obnubila seu entendimento, dificultando, assim, sua transformação objetiva. Daí a oposição do autor aos sectários, sejam eles de direita ou de esquerda, pois, independentemente de onde venha, "[...] a sectarização é um obstáculo à emancipação dos homens." (FREIRE, 2013, p. 25).

Nesse sentido, a radicalização, em Freire, assume compromisso com a emancipação humana. No entanto, não se trata de compromisso tutelado, construído de cima para baixo, de um que sabe mais para um que sabe menos, mas algo erigido em comunhão de esforços e em aprendizado mútuo. Esse comprometimento assume a essência do seu significado, por isso, mesmo radical, e não se realiza só no campo do discurso, mas também ao se materializar na prática construída por Freire no seu projeto 
de formação da classe popular, da pedagogia do oprimido, como "aquela que tem de ser forjada com ele e não para ele, enquanto homens ou povos, na luta incessante de recuperação de sua humanidade." (FREIRE, 2013, p. 33).

Para cumprir tal tarefa, é necessário, contudo, a prática educativa que favoreça a atividade dos educandos, que tenha o mundo e a realidade como objetos de reflexão. Ao refletir sobre essa realidade, os oprimidos podem melhor compreendê-la e, assim, transformá-la. Não se trata de uma reflexão sobre qualquer realidade, mas exatamente de uma dimensão da realidade que faz a classe popular ser oprimida e que produz também o opressor. Agindo assim, conforme o autor, os oprimidos se engajarão na sua libertação, pois participarão de seu desvelamento em processo dialógico com o mundo e com os outros.

Compreendemos a radicalidade em Freire como um movimento de ir à raiz das coisas, buscando entender seus significados, algo que vai além do discurso vazio, da simples retórica. Ao assumir a radicalidade como estilo de vida, Paulo Freire não se refere apenas à possibilidade da reflexão da realidade ou da compreensão melhor do mundo, correndo o risco de desviar-se para outra direção ou sentido no momento de se concretizar, mas a uma radicalidade condicionada à efetivação do pensamento na própria prática. A radicalidade, entendida assim, se assemelha a um instrumental utilizado para apreender, descrever e transformar a realidade numa relação dialética com vistas à emancipação.

$\mathrm{Na}$ seção seguinte discutimos a radicalidade humanizadora da educação freireana e os limites e as possibilidades de implantação desse projeto com vistas à emancipação humana no cenário atual brasileiro.

POSSIBILIDADES E LIMITES DA RADICALIDADE HUMANIZADORA FREIREANA NA EDUCAÇÃO ATUAL

Moacir Gadotti, no prefácio do livro de Scocuglia (2019), "A história das ideias de Paulo Freire e a atual crise dos paradigmas", afirma que as produções freireanas são erigidas em torno de um único objeto de pesquisa, qual seja, a educação como instrumento de libertação, o que significa a defesa da educação popular, radical, democrática e genuinamente humanizadora.

Nesse projeto, que tem a radicalidade como instrumento de reflexão e ação com vistas à educação para a transformação da realidade e para a emancipação humana, Paulo Freire amplia significativamente os horizontes da sua produção escrita, ganhando cada vez mais reconhecimento e rompendo as fronteiras da educação não formal. Sua pedagogia, com fundamentos consistentes em propostas curriculares de perspectiva crítica, de acordo com Saul (1998), materializa a matriz que fundamenta o paradigma curricular de racionalidade crítico-emancipatória.

Se outrora a pedagogia freireana inaugurava um novo paradigma pedagógico na América Latina, na atualidade, em termos globais, seu legado fundamenta o trabalho coletivo em processo não só de edificação, mas de reinvenção nos diferentes movimentos de luta e organização das classes populares no mundo todo. Isso pode ser comprovado pela "Pedagogia do oprimido", obra que se transformou num projeto 
coletivo da humanidade, especialmente por traduzir o sentimento, os valores, as ideias e os projetos daqueles que lutam juntos e se solidarizam por um mundo mais justo e humanizado para todos.

Nosso destaque em torno dessa obra foi inspirado em depoimento dado pelo próprio Paulo Freire no livro "Pedagogia da Esperança: um reencontro com a Pedagogia do Oprimido":

Talvez, porém, deva deixar claro aos leitores e leitoras que, ao reportar-me à Pedagogia do oprimido e falar hoje das tramas vividas nos anos 70, não estou assumindo uma posição saudosista. $\mathrm{Na}$ verdade, o meu encontro com a Pedagogia do Oprimido não tem o tom de quem fala do que já foi, mais do que está sendo. [...] As tramas, os fatos, os debates, discussões, projetos, experiências, diálogos de que participei nos anos 70, tendo a Pedagogia do oprimido como centro, me aparecem tão atuais quanto outros a que me refiro dos anos 80 e de hoje (FREIRE, 1994, p. 13, grifos nossos).

Em suas análises, Paulo Freire admite que a realidade que engendrou a produção da Pedagogia do Oprimido não foi superada, ainda continua produzindo todas as mazelas alvo de críticas do autor nos anos de 1970. Além disso, essa conclusão do autor reafirma para nós, educadores, o quão atuais são suas ideias e como ainda se faz necessário que continuemos tomando seu pensamento e sua prática como referenciais importantes, particularmente no contexto brasileiro, em que assistimos o fortalecimento de reformas educacionais neoliberais e conservadoras que a todo custo tentam impor um novo paradigma de controle da educação nacional.

Nessa direção e considerando o cenário atual brasileiro, é válido indagarmos: Quais seriam os limites e as possibilidades da radicalidade humanizadora da educação freireana no engendramento de práticas educativas na direção da emancipação humana na atualidade?

Para responder a essa questão, comecemos destacando algumas das características essenciais da pedagogia freireana: a indissociabilidade entre ensino, aprendizagem e conscientização, ou, ainda, a indissociabilidade entre o pedagógico e o político. Essa indissociabilidade, considerada aqui como princípio, é a característica fulcral que faz da pedagogia freireana um projeto radicalmente humanizador, porque as práticas educativas pautadas nessa indissociabilidade possibilitam aos indivíduos assumirem a condição de seres ontocriativos. E o que significa ser ontocriativo na pedagogia freireana?

Significa entender-se como sujeito histórico, ser alguém em permanente processo de constituição e mudança. Alguém que se constitui ao estar no mundo e com o mundo, ao mesmo tempo que ajuda a edificar esse mundo. Alguém que abandona a posição de mero expectador para assumir a condição de criador, de produtor de si e da realidade humano-social. Alguém que se realiza como ser na interação com o seu meio, criando e recriando "[...] respondendo a seus desafios, objetivando-se a si próprio, discernindo, transcendendo, lança-se o homem num domínio que lhe é exclusivo - o da história e o da cultura." (FREIRE, 2015, p. 43). 
É a indissociabilidade entre o pedagógico e o político que fundamenta práticas pedagógicas desenvolvidas com a intencionalidade de garantir a assunção do homem no domínio da realidade socio-histórica. Em termos objetivos, Paulo Freire nos oferece um projeto educativo que leva os indivíduos a assumirem a sua humanidade, a fazerem parte desse mundo, apropriando-se dos temas fundamentais da sua época, reconhecendo suas tarefas concretas, assumindo, assim, atitude crítica em relação aos problemas que constituem o tecido da realidade social, evitando com isso serem manipulados "pelas já referidas prescrições que the são impostas ou quase sempre maciamente doadas." (FREIRE, 2015, p. 46).

É o princípio da indissociabilidade entre o pedagógico e o político que medeia a superação da manipulação das massas porque possibilita que professores e alunos deixem de seguir tutelados e apreendam a realidade de forma crítica, compreendendo a importância da sua participação na definição dos rumos da sociedade, uma vez que é chegado o momento de assumir posição e ação críticas.

A atitude crítica, segundo Freire $(2015$, p. 61), só se faz existir mediante um passo decisivo: a superação da "[...] consciência dominantemente transitivo-ingênua para a dominantemente transitivo-crítica [...]", algo somente alcançado como resultado de um "[...] trabalho educativo crítico com essa destinação". Em outras palavras, Freire nos adverte que a educação destinada a homens e mulheres que realmente importa e tem valor para suas vidas é a que se pauta no objetivo de fazê-los compreender que a realidade concreta existe como resposta às intervenções humanas, colaborando para que superem a consciência ingênua de que vivem em um mundo dado e não em um mundo posto. Mas isso não ocorre de forma natural, é necessário educar com vistas a essa conscientização crítica para a compreensão do caráter histórico da ação humana:

\footnotetext{
A realidade social, objetiva, que não existe por acaso, mas como produto da ação dos homens, também não se transforma por acaso. Se os homens são os produtores desta realidade e se esta, na "inversão da práxis", se volta sobre eles e os condiciona, transformar a realidade opressora é tarefa histórica, é tarefa dos homens (FREIRE, 2013, p. 39).
}

A concepção do ser humano como ser histórico, produto e produtor da realidade na qual se encontra, permite compreender a possiblidade de transformação da realidade pelos próprios seres humanos. Portanto, a práxis pedagógica freireana é radicalmente humanizadora porque compreende a necessidade de superação da exploração humana, das injustiças, não somente pela libertação do oprimido, mas também do opressor, indo de encontro à concepção fatalista da história. Por conseguinte, na sua práxis pedagógica, está explícito o caráter político, ou seja, a concepção de ser humano e de sociedade que defende.

Essa práxis pedagógica não pode ser dissertadora, impositora, mas, sim, do diálogo, da oportunidade da fala, de ser ouvido e ouvir. Impõe-se, então, outra característica fundamental na pedagogia freireana: a dialogicidade, que coloca a pedagogia libertadora em contraposição à "educação bancária". 
Ao negar a oportunidade de fala ao outro, ao impor uma prática educativa antidialógica, a educação bancária não considera os educandos sujeitos portadores de saber. Nessa acepção, os saberes serão concedidos, ou seja, doados por aqueles considerados sábios para os não sábios. Essa compreensão remete à etimologia da palavra aluno - sem luz, nesse caso, sem saber. O professor seria então essa luz portadora de saber concedida para esse indivíduo. Conforme o educador pernambucano, isso representa a alienação da ignorância, uma posição estagnada em que a ignorância está presente sempre no outro, nesse caso, no educando. Por isso mesmo que, ao ser o único possuidor desse saber, o professor deve sempre doá-lo, gerando a contradição educador-educandos.

Na direção de superar a contradição educador-educando, Freire (2013) propõe uma prática educativa mais horizontal, centrada no diálogo, uma educação libertadora. Por meio da problematização da realidade, os indivíduos vão tendo voz, vão dialogando e demonstrando saberes dessa realidade, possibilitando o rompimento de um cariz vertical presente na educação bancária.

Ao romper com as práticas de transmissão, doação e das narrativas de conhecimentos, a educação libertadora busca conhecer a realidade por meio de uma prática dialógica problematizadora. Nesse sentido, a educação libertadora supera a contradição entre educador e educandos, ao propor a realidade dos indivíduos como objeto a ser conhecido por meio do diálogo, estratégia que possibilita que educador e educandos expressem saber sobre o objeto cognoscível. Portanto, sem a educação problematizadora "[...] não é possível a relação dialógica, indispensável à cognoscibilidade dos sujeitos cognoscentes, em torno do mesmo objeto cognoscível". (FREIRE, 2013, p. 79).

Tanto a indissociabilidade entre o pedagógico e o político quanto a dialogicidade presente na "Pedagogia do oprimido" trazem possibilidades de engendrar práticas educativas na direção da emancipação humana no contexto atual, pois tratamse, segundo Freire (2013, p. 77), da educação "[...] que, servindo à libertação, se funda na criatividade e estimula a reflexão e a ação verdadeiras dos homens sobre a realidade, responde à sua vocação, como seres que não podem autenticar-se fora da busca e da transformação criadora".

Não obstante à constatação da importância da educação crítica fundamentada nos princípios da pedagogia freireana, presenciamos, nos últimos anos, uma onda reacionária e conservadora em nosso país, que impõe limites à penetração desse pensamento ao impetrar acusações e críticas com a evidente intenção de defesa de determinada educação exclusivamente a serviço da exploração e dos interesses mercadológicos: a educação para formação de competências.

Nessa direção, as políticas educacionais curriculares no Brasil, desenvolvidas predominantemente nos anos de 1990 e em voga nos dias atuais, hegemonizadas pelos aparelhos privados do empresariado nacional e internacional, bem como os organismos multilaterais, tiveram como foco enfraquecer o currículo, esvaziando seus conteúdos, considerados clássicos e reduzindo as áreas das Humanidades em razão de supostas necessidades imediatas da classe trabalhadora, quando, de fato, o que se pretende é o fortalecimento da lógica do capital.

Eis aí a importância de não desvincularmos o currículo da constituição sóciohistórica no qual está inserido, pois ele não surge aleatoriamente, mas de uma 
necessidade social, sobretudo econômica. Atualmente, a disputa no âmbito educacional, de um modo geral, tem se intensificado no contexto das políticas neoliberais muito bem alinhadas aos interesses do empresariado e do capital. O cenário da tal disputa mira na formação do cidadão por caminhos opostos à libertação humana, de tal modo que a formação crítica e emancipatória perdeu fôlego no campo educacional diante das reformas educacionais já aprovadas e/ou em curso no Brasil.

A esse respeito, enfatizamos aqui a implantação da Base Nacional Comum Curricular (BNCC), fruto de participação de professores, alunos e comunidade escolar, que foi sendo descartada a cada versão quando da sua elaboração, ainda que o discurso midiático afirme exatamente o contrário e ao mesmo tempo propague algo que soe moderno, inovador e necessário. A aprovação da BNCC por meio da consulta duvidosa utilizada para legitimar a participação popular é mais um capítulo desse conturbado processo. Vários especialistas, intelectuais, associações da sociedade civil e professores, que inicialmente participaram significativamente, foram sendo substituídos, sendo que a última versão do documento resulta na presença maciça das fundações e representantes de empresas e grupos privados.

No tocante à sua organização, a questionada versão aprovada da BNCC apregoa a importância do ensino assentado no desenvolvimento de "competências e habilidades" (BRASIL, 2017a, p. 15) e na seção "Os fundamentos pedagógicos da BNCC" o referido documento aponta que os conteúdos curriculares devem se pautar no desenvolvimento de competências, sendo que "ser competente significa ser capaz de, ao se defrontar com um problema, ativar e utilizar o conhecimento construído" (BRASIL, 2017 , p. 16). Diante do exposto, somos levados a entender que a BNCC converge para as intencionalidades dos organismos internacionais, que prezam pela ideologia neoliberal, visando à formação de sujeitos flexíveis, moldáveis e adaptáveis às necessidades do mercado, em detrimento da formação emancipatória do cidadão.

É nesse sentido que Marsiglia, Pina, Machado e Lima (2017, p. 118) denunciam que o documento oficial brasileiro orienta processos de adaptação dos alunos ao mercado de trabalho ou, mais propriamente, ao "empreendedorismo", o que tem servido à naturalização do desemprego crescente e a precarização da formação escolar desses indivíduos. Em suma, a pedagogia das competências dita o fazer pedagógico, orientado para a atividade empreendedora em virtude da crise estrutural que atravessa a economia. Nessa direção, essa pedagogia estabelece um caráter hegemônico representado nos vários documentos que balizam a prática pedagógica, ajudando a perpetuar assim o cenário de desigualdades que assola a sociedade. No entanto, é importante destacar que a conservação das injustiças e da exploração não está manifestada de forma explícita nas reformas educacionais, pelo contrário, apresenta-se sempre como inovação atrativa.

Assumindo a aparência de inovadora e atrativa, a atual reforma do ensino médio aprovada por meio da Lei n. $13.415 / 2017$, de acordo com Branco et al. (2018, p. 15), não está voltada para atender às necessidades históricas daqueles que o frequentam, conforme proclamado, "[...] mas sim, direcionar o ensino para atender às demandas de mercado, que requerem trabalhadores flexíveis capazes de se adequarem às rápidas mudanças científico-tecnológicas que ditam o dinamismo no setor 
produtivo".

Sob o discurso que o governo denomina de protagonismo juvenil, liberdade de escolha e outras narrativas construídas para ludibriar a população, questionamo-nos: a que serve a propagação da premissa de que o Novo Ensino Médio atende aos interesses da juventude brasileira? A que público essa escola se destina?

Segundo Jaqueline Moll (2017, p. 13), em seu artigo "Reformar para retardar: a lógica da mudança no E.M.", essa escola reformada, como discorremos, e sob um slogan falacioso, só vem a retardar avanços já encaminhados e impedir que outros se consolidem. Essas reformas, implementadas de forma acelerada, desconsideram os avanços coletivos, a participação, as contribuições dos vários atores da sociedade, bem como as reais necessidades da juventude brasileira, algo fundamental para a construção de um projeto de educação que incorpore a dialogicidade como premissa e que tenha como objetivo fundamental a humanização dos jovens que frequentam a escola de educação básica.

É, portanto, nesse cenário de lutas e de forças antagônicas que a radicalidade humanizadora de Paulo Freire, presente na "Pedagogia do Oprimido" e na "Educação como prática de Liberdade", nos possibilita alicerçar práticas educativas que rompam radicalmente com a educação escolar restrita aos conteúdos cristalizados, e que, em nome da educação problematizadora, possibilite o diálogo, o pensar autêntico, a investigação crítica e, desse modo, "[...] uma reorientação curricular democrática e participativa no sentido de tornar crítica a consciência popular e a intencionalidade ético-política das ações do cotidiano escolar (SAUL; SILVA, 2014, p. 2071).

Educadores, estudiosos e curriculistas empenhados em defender a educação emancipatória de vários países, dentre eles: Enrique Dussel, no México; Licínio Lima e António Nóvoa, em Portugal; Michael Apple, Henry Giroux e Peter MacLaren, nos Estados Unidos, testemunham que Paulo Freire deixou-nos um legado que nos ajuda a enfrentar e a resistir a diferentes formas de opressão e dominação (SAUL, 2008). Deixanos, ainda, a compreensão de que o essencial no enfrentamento de todas as formas de opressão e na luta pela superação das relações de poder é o engajamento com uma prática educativa comprometida com a realização da máxima humanização de homens e mulheres, isto é, uma prática educativa que nos conscientize a todas e a todos das manobras da cultura opressora; que produza um processo cultural que, definitivamente, faça emergir na história do povo brasileiro um novo ethos cultural. Em suma, uma prática educativa que engendre, de modo crítico e criativo, as características fundamentais dessa nova cultura, a saber: colaboração; união para a liberdade; organização dos oprimidos e síntese cultural.

\section{CONSIDERAÇÕES FINAIS}

O presente artigo objetivou analisar a concepção de radicalidade humanizadora em Freire e as determinações que este conceito engendra às práticas educativas com vistas à emancipação humana.

A pesquisa apontou que a radicalidade humanizadora em Paulo Freire não tem nenhuma relação com a pecha extremista que a ele tentam imputar exatamente aqueles que se contrapõem ao diálogo, à aceitação das diferenças, à construção de uma 
sociedade mais justa. São esses indivíduos e grupos, aos quais Freire denominou de sectários, que adotam posições extremistas, anulando a possiblidade de tanto opressores quanto oprimidos construírem outra possibilidade de sociedade.

Com efeito, a radicalidade de Paulo Freire é humanizadora, porque, ao defender as práticas educativas centradas na indissociabilidade entre o pedagógico e o político, e na dialogicidade, defende a emancipação humana. Nada mais humanizador do que defender a possibilidade de emancipação e de ser mais dos indivíduos, o que vai de encontro à educação centrada na formação de competências.

A pedagogia de Paulo Freire, exatamente por ser radicalmente humanizadora, se constitui como instrumento que associa a leitura da realidade em sua essência para orientar a prática educativa coerente com essa compreensão para sua transformação. Em tempos de avanços das políticas neoliberais, de projetos educativos que longe de promover a transformação radical da sociedade, ao contrário, orientam a adaptação e a aceitação passiva de tal ordem, o nome e as ideias de Paulo Freire representam grave ameaça, por isso elas precisam ser banidas, criminalizadas, demonizadas. Numa sociedade dominada pela necropolítica', não há espaço para projetos educativos humanizadores.

A pedagogia de Paulo Freire é uma pedagogia da práxis exatamente porque fornece elementos teóricos e práticos importantes ao enfrentamento do cenário atual em que vivemos, marcado pela pandemia da Covid-19. Tal cenário, que expõe mais ainda as contradições inerentes ao modelo capitalista, representado na valorização dos aspectos econômicos em detrimento da vida, levando-nos a continuar questionando: em uma sociabilidade atravessada por concepções de mundo sectárias, pela naturalização da exploração do ser humano e pela desesperança imobilizadora, como apropriar-se do legado freireano? Como efetivá-lo em práticas educativas em uma escola explicitamente comprometida com a reprodução das condições de exploração?

Educadoras e educadores têm na trajetória de vida e obra de Paulo Freire elementos significativos para iniciar essa tarefa, elementos presentes na incansável busca de concretizar suas reflexões sobre o ser humano, a sociedade e o papel da educação na prática. Sigamos, então, buscando encaminhamentos a partir de Paulo Freire, bem como criando as condições para educação rumo à emancipação que permita a conscientização sobre as manobras de opressão, reunindo, sobretudo, teoria e prática, ação e reflexão, enfim, uma práxis transformadora.

Artigo recebido em: 28/03/2021

Aprovado para publicação em: 29/06/2021

THE CURRENCY OF THE RADICALISM IN PAULO FREIRE IN THE FIRST WRITINGS AT THE EXILE: OUTLINING FOR EDUCATIVE PRACTICES IN THE DIRECTION OF HUMAN'S EMANCIPATION

ABSTRACT: This text aims to analyze the conception of humanizing radicalism in Paulo Freire and 
MARQUES, E. de S. A.; OLIVEIRA, J. S. C. de; BONFIM, L. J. S.

the determinations that this concept engenders to the educative practices intending to the human's emancipation. It results from bibliographical research in the works "Pedagogia do Oprimido" (2013) and "Educação como prática para liberdade" (2013), and in the reflections of appropriators. The humanizing radicalism in Paulo Freire is a product of his praxis, result of his quest for better comprehending the reality's elements and to act in a consistent manner steering to the transformation of the social reality. Indeed, the radicalism of Freire is humanizing, because it defends human's emancipation. It is humanizing to safeguard the possibility of emancipation and of the constitution of being more of the individuals starting from the collective and active building, directly involving the oppressed.

KEYWORDS: Freirean Pedagogy. Radicalism. Social Transformation. Educative Practices.

LA ACTUALIDAD DE LA CONCEPCIÓN DE LA RADICALIDAD EN PAULO FREIRE EN LOS PRIMEROS ESCRITOS EN EL EXILIO: ESBOZOS PARA LAS PRÁCTICAS EDUCATIVAS EN DIRECCIÓN A LA EMANCIPACIÓN HUMANA

RESUMEN: Este texto tiene como objetivo analizar la concepción de la radicalidad humanizadora en Paulo Freire y las implicaciones de este concepto para las prácticas educativas orientadas a la emancipación humana. Es el resultado de la investigación bibliográfica en las obras " Pedagogia do Oprimido " (2013) y " Educação como prática para liberdade " (2015), y en las reflexiones de los apropiadores. La radicalidad humanizadora en Freire es el producto de su praxis, fruto de su búsqueda para comprender mejor los elementos de la realidad y actuar conscientemente hacia la transformación de la realidad social. De hecho, la radicalidad de Freire es humanizadora, porque defiende la emancipación humana. Es humanizador salvaguardar la posibilidad de emancipación y de la constitución del ser y de los individuos desde la construcción colectiva y activa, involucrando directamente a los oprimidos.

PALABRAS CLAVE: Pedagogía Freireana. Radicalidad. Transformación Social. Prácticas Educativas.

\section{NOTAS}

1 - Para Achille Mbembe (2018), o conceito filosófico de necropolítica faz referência ao uso do poder pelo Estado em ditar quem pode viver e os que devem morrer. Em outras palavras, consiste na distribuição desigual da oportunidade de viver e morrer na sociabilidade capitalista atual.

\section{REFERÊNCIAS}

BRANCO, Emerson Pereira et al. Uma visão crítica sobre a implantação da Base Nacional Comum Curricular em consonância com a reforma do Ensino Médio. In: Revista Debates em Educação, Programa de Pós-Graduação em Educação da Universidade Federal de Alagoas, Maceió, v. 10, n. 21, p. 1-24, mai./ago. 2018. Disponível em: 
$<$ https://www.seer.ufal.br/index.php/debateseducacao/article/view/5087>. Acesso em: 20 jan. 2021.

BRASIL. Base Nacional Comum Curricular. 2017a. Disponível em: <http://agbcampinas.com.br/site/http://agbcampinas.com.br/site/wpcontent/uploads/2017/08/BNCC_publicacao.pdf>. Acesso em: 6 jan. 2021.

BRASIL Lei no 13.415, de 16 de fevereiro de 2017b. Altera as Leis № 9.394, de 20 de dezembro de 1996, que estabelece as diretrizes e bases da educação nacional, e 11.494, de 20 de junho 2007, que regulamenta o Fundo de Manutenção e Desenvolvimento da Educação Básica e de Valorização dos Profissionais da Educação, a Consolidação das Leis do Trabalho - CLT, aprovada pelo Decreto-Lei № 5.452, de $1^{\circ}$ de maio de 1943, e o Decreto-Lei № 236, de 28 de fevereiro de 1967; revoga a Lei № 11.161, de 5 de agosto de 2005; e institui a Política de Fomento à Implementação de Escolas de Ensino Médio em Tempo Integral. 2017b. Disponível em: <http://www.planalto.gov.br/ccivil_03/_ato2015-2018/2017/lei/L13415.htm>. Acesso em: 7 jan. 2021.

DICIO. Dicionário on-line de Português. Disponível em: <https://www.dicio.com.br/radicalismo/>. Acesso em: 6 jan. 2021.

FREIRE, Paulo. Educação como prática da liberdade. São Paulo: Paz e Terra, 2015.

FREIRE, Paulo. Pedagogia da Esperança: um reencontro com a Pedagogia do Oprimido. Rio de Janeiro: Paz e Terra, 1994.

FREIRE, Paulo. Pedagogia do oprimido. São Paulo: Paz e Terra, 2013.

GADOTTI, Moacir. A voz do biógrafo brasileiro. In: GADOTTI, Moacir (Org.). Paulo Freire: uma biobibliografia. São Paulo: Cortez, 1996. p. 69-116.

MARSIGLIA, Ana Carolina Galvão; PINA, Leonardo Docena; MACHADO, Vinícius de Oliveira; LIMA, Marcelo. A base nacional comum curricular: um novo episódio de esvaziamento da escola no Brasil. Germinal: Marxismo e Educação em Debate, Salvador, v. 9, n. 1, p. 107-121, abr. 2017.

MBEMBE, Achille. Necropolítica: biopoder, soberania, estado de exceção, política da morte. Tradução de Renata Santini. São Paulo: N-1 edições, 2018. 80 p.

MOLL, Jaqueline. Reformar para retardar: A lógica da mudança no EM. Revista Retratos da Escola, Brasília, v. 11, n. 20, p. 61-74, jan./jun. 2017. Disponível em: <http://www.esforce.org.br/>. Acesso em: 10 jan. 2021.

RODRIGUES, Neidson. Entrevista Paulo Freire: Crítico, radical e otimista. Revista Presença Pedagógica, Belo Horizonte, Ano I, n. 1, p. 5-12, jan./fev. 1995. SAUL, Ana Maria. A construção do currículo na teoria e prática de Paulo Freire. In: APPLE, Michael; NÓVOA, António (Org.). Paulo Freire: política e pedagogia. Porto-Portugal: Porto Editora, 1998. p. 151-165.

SAUL; Ana Maria; SILVA, Antonio Gouvêa da. A matriz de pensamento de Paulo Freire: um crivo de denúncia-anúncio de concepções e práticas curriculares. Revista e-Curriculum, Programa de Pósgraduação Educação: Currículo - PUC, São Paulo, v. 12, n. 3, p. 2064-2080, out./dez. 2014. 
MARQUES, E. de S. A.; OLIVEIRA, J. S. C. de; BONFIM, L. J. S.

Disponível em: <http://revistas.pucsp.br/index.php/curriculum>. Acesso em: 20 jan. 2021.

SAUL, Ana. Maria. Currículo. In: STRECK, D. R.; REDIN, E. ZITKOSKI, J. J. (Orgs.) Dicionário Paulo Freire. Belo Horizonte: Autentica Editora, 2008, p. 120-121.

SCOCUGLIA, Afonso Celso. A história das ideias de Paulo Freire e a atual crise dos paradigmas. 7. ed. João Pessoa: Editora da UFPB, 2019.

WILLIANSON, Guilhermo. Paulo Freire: 1964-1969. Sua passagem pelo Chile e o Chile pelo qual passou. In: GADOTTI, Moacir. (Org.). Paulo Freire: uma biobibliografia. São Paulo: Cortez, 1996. p. 184-187.

Eliana de Sousa Alencar Marques: Doutorado em Educação pela Universidade Federal do Piauí. Professora do Programa de Pós-graduação em Educação da Universidade Federal do Piauí, vinculada à linha de pesquisa: Formação humana e processos educativos. Professora adjunta do Curso de Pedagogia no Departamento de Métodos e Técnicas de Ensino na Universidade Federal do Piauí. Diretora do Centro de Ciências da Educação (2021-2025).

Orcid: https://orcid.org/0000-0002-4990-4487

E-mail: esalencar123@ufpi.edu.br

Josiane Sousa Costa de Oliveira: Professora do Instituto Federal de Educação, Ciência e Tecnologia do Maranhão - IFMA, atuando nas disciplinas pedagógicas na área da Educação. Mestrado em educação e Doutoranda do Programa de Pós-graduação em Educação da Universidade Federal do Piauí. Pesquisadora do Núcleo de Estudos e Pesquisas Histórico Críticas em Educação e Formação Humana - NEPSH.

Orcid: https://orcid.org/0000-0001-5090-310X

E-mail: josiane.oliveira@ifma.edu.br

Luiz Jesus Santos BonfiM: Professor da Universidade Federal do Piaú (UFPI) no Campus Ministro Petrônio Portela no Centro de Ciências da Educação (CCE) em Teresina-PI ministrando disciplinas no Curso de Licenciatura em Educação do Campo e em outras licenciaturas nas áreas de Fundamentos da Educação e Disciplinas Pedagógicas. Mestre em educação e atualmente cursa doutorado em Educação - PPGED/UFPI. Integra - Núcleo de Estudos e Pesquisas Histórico Críticas em Educação e Formação Humana NEPSH.

Orcid: https://orcid.org/0000-0003-4782-1917

E-mail: luizbonfim@ufpi.edu.br

Este periódico utiliza a licença Creative Commons Attribution 3.0, para periódicos de acesso aberto (Open Archives Initiative - OAI). 